\title{
Editorial
}

\section{Understanding and Managing Our Earth through Integrated Use and Analysis of Geo-Information}

\author{
Wolfgang Kainz \\ Department of Geography and Regional Research, University of Vienna, Universitätsstraße 7, \\ A-1010 Vienna, Austria; E-Mail: wolfgang.kainz@univie.ac.at; Tel.: +43-1-4277-48640; \\ Fax: $+43-1-4277-9486$
}

Received: 2 September 2011 / Accepted: 2 September 2011 / Published: 8 September 2011

All things in our world are related to some location in space and time, and according to Tobler's first law of geography "everything is related to everything else, but near things are more related than distant things" [1]. Since humans exist they have been contemplating about space and time and have tried to depict and manage the geographic space they live in. We know graphic representations of the land from various regions of the world dating back several thousands of years. The processing and analysis of spatial data has a long history in the disciplines that deal with spatial data such as geography, surveying engineering, cartography, photogrammetry, and remote sensing. Until recently, all these activities have been analog in nature; only since the invention of the computer in the second half of the 20th century and the use of computers for the acquisition, storage, analysis, and display of spatial data starting in the 1960s we speak of geo-information and geo-information systems.

The possibility to acquire and store spatial data in digital form created many possibilities and opportunities to use digital data for various purposes that were hitherto difficult to realize with analog means. For many years we had to make do with the small amount of digital data available and with limited software functionality; most of all, however, with limitations of the hardware and computing power. Much progress was achieved in the 1980s and 1990s with regard to development of new algorithms, data structures, and the establishment of a geo-information theory, finally leading to what we now call geo-information science. Today, we are not only faced with an enormous flood of data but also with global problems of environmental and climate change as well as natural disasters. How do we create and store digital models of our world in ever more detail? How do we respond to hazards and disasters appropriately when the technical infrastructure has been destroyed? How can we display global dynamic phenomena in an appealing way? What policies and infrastructure do we need to provide necessary information and to allow citizens access to such information? How do we deal with 
uncertain and erroneous data? How do we detect and identify patterns in data sets that can provide new insight and better understanding of the underlying phenomena? All these questions and many more are addressed by geo-information systems and science.

The new ISPRS International Journal of Geo-Information will publish regular research papers, reviews and communications. Our aim is to encourage scientists to publish their experimental and theoretical results in as much detail as possible. Geo-information covers a wide range of disciplines from geography, remote sensing, cartography, surveying engineering, photogrammetry, mathematics, and physics, to social sciences, philosophy, psychology, cognitive science, and linguistics. Many application domains from archaeology to zoology use geo-information technology for their particular purposes. We expect and invite contributions from, but not limited to, the domains of data collection and acquisition, data structures and algorithms, spatio-temporal databases, spatial analysis, data mining, and decision support systems, visualization theory and technology in real and virtual environments, cartography, location based services, uncertainty handling in spatial data, topology, geo-computation, geo-telematics, spatial information infrastructures, interoperability and open systems, as well as applications of geo-information technology.

The International Society for Photogrammetry and Remote Sensing (ISPRS) is a "non-governmental international organization devoted to the development of international cooperation for the advancement of knowledge, research, development, education and training in the photogrammetry, remote sensing and spatial information sciences, their integration and applications, to contribute to the well-being of humanity and the sustainability of the environment" [2]. ISPRS has joined with the publisher MDPI (Multidisciplinary Digital Publishing Institute) to establish this new open access journal, which will provide all the advantages of open access journals, i.e., fast review and reasonable publication costs for the authors and free access for all. For the years 2011 and 2012 publication will be free for all accepted papers.

As Editor-in-Chief I would like to encourage all scientists from around the world to submit contributions to this new journal. We live in a globalized world and the scientific exchange among people from all countries, regardless of the continent or political system, whether rich or poor, big or small, is of utmost importance when we want to tackle the global problems we face today and will face in the future. My wish is to stimulate such exchange by providing this platform for high-quality papers.

\section{References}

1. Sui, D.Z. Tobler's first law of geography: A big idea for a small world? Ann. Assoc. Am. Geogr. 2004, 94, 269-277.

2. International Society for Photogrammetry and Remote Sensing (ISPRS). Available online: http://www.isprs.org/ (accessed on 2 September 2011).

(C) 2011 by the authors; licensee MDPI, Basel, Switzerland. This article is an open access article distributed under the terms and conditions of the Creative Commons Attribution license (http://creativecommons.org/licenses/by/3.0/). 